\title{
The Challenges in Implementing Mixed Economy of Care Practices in Child Welfare Network in Malaysia
}

\author{
Siti Hajar Abdul Rauf ${ }^{*}$, Siti Hajar Abu Bakar Ah², Haris Abd Wahab ${ }^{3}$, Siti Balqis \\ Mohd Azam ${ }^{4}$ \\ ${ }^{1}$ Faculty of Applied Social Sciences, University Sultan Zainal Abidin, Terengganu, Malaysia \\ ${ }^{2,3}$ Faculty of Arts and Social Science, University Malaya, Kuala Lumpur, Malaysia \\ ${ }^{4}$ Faculty of Law, University Malaya, Kuala Lumpur, Malaysia \\ *Corresponding author. Email: hajarrauf@unisza.edu.my
}

\begin{abstract}
The Social networks play a very important role in the well-being of children. This is because; the welfare network serves as a charitable service provider to meet their needs. Child welfare networks include family members, children, schools, peers, neighbors, community members and institutions offering health, education, health, food and drink services, love, safety, protection and a healthy environment. This article describes the network mapping of child welfare services in the custody of public institutions. A study was conducted to explore the practice of implementing the welfare services network of children at STB Marang, Terengganu Malaysia using the qualitative design of the Grounded Theory to obtain the raw data. A set of interview protocols have been developed as a guide to conducting face-to-face and deep interviews with 30 respondents of 24 different agencies. The main findings of the study found that although public custody in Malaysia practiced a mixed economy of care approach, service network operations were in conflict with the mixed economy of care approach adopted. As a follow-up to the findings of this study, the Social Network Development Model was developed. This model can be a productive tool in developing an integrated welfare network for children in Malaysia.
\end{abstract}

Keywords: social networks, mixed economy of care, welfare services, children

\section{INTRODUCTION}

Sociologists agree that human beings are "social animals" who cannot live alone without their community, without interacting or unconnected with other individuals. Functionalist members think that individuals cannot exercise their functions, roles and social responsibilities if they live isolated from other members of society. In other words, individuals need to connect or build relationships with other individuals, social institutions and other social organizations in ensuring that all their living and social needs are met [1]. Relationships formed among individuals with individuals, institutions and other organizations around them are called social networks [2]. Individual ability fulfils the needs of his life depending on the state of his social network. If he has a good social network; illustrated, for example, by good social relationships with his family, his neighbourhood community, the workplace and the social services agencies around him, these individuals can easily settle their life needs and deal with the deficit needs of theirs [3]. This is because all individuals, institutions or organizations in this social network work together as a team in preparing and delivering the social services required by the individual [1].

In the context of children, [4] emphatically says that the quality of their well-being depends largely on the social network of the social environment in which they live [5]. The welfare network of children is a relationship formed between children and all those who serve as child welfare service providers to meet their needs [6]. Child welfare networks include family members of the children themselves, schools, peers, neighbours, community members and institutions offering education, spiritual, health, food and drink, compassionate, safety, protection and a healthy environment. All sectors and agencies interact, connect and merge into a comprehensive welfare service system for children [7]. This situation clearly shows social networking is important in meeting the needs of children's lives. 
The integrated network of children helps children meet the needs of their lives and social needs for selfdevelopment, empowering internal assets, addressing problems that arise and helping them overcome and manage the stresses experienced [8] through the implementation of mixed economy of care [9]. As stated by [10], mixed economy of care is combinations of ways in which benefits and services can be provided and funded; including public sector, the private and voluntary sector and informal care. There is a variety of ways in which services are accessed or purchased, from the so-called 'coerced collective demands', when needs and expectations force the community to provide or purchase things collectively, paid for through taxation, through funding from charitable trusts, businesses and individual purchases, to individual donations of money and time. Both of provider and purchaser interact in the form of transaction to define the pattern of the mixed economy [11]. Nevertheless, the main objective of a mixed economy of care are to provide a better choice for individuals, more flexibility in the range of services on offer to respond to individuals' needs, improved cost-effectiveness and quality of services. Mixed economy of care distributes goods and services to where they are most needed because it allows prices to measure supply and demand [10].

In the new mixed economy of welfare, the contracting out of service delivery may involve the public, private, voluntary and community sectors, in combinations that vary spatially [12]. The diverse modes of service delivery have been a shift in public funding mechanisms for the voluntary and community sector including social enterprises to deliver public services from grants to contracts [13]. Meanwhile, contract funding is awarded for the provision of a particular service and is conditional upon a mutually binding agreement with a formal legal status. The contract becomes a big challenge in implementing mixed economy of care. In addition, this "new contract culture' has resulted in significant changes in both the organization and operation of organizations [11]. While some such services (especially health care and social care) are delivered through a formal organizational structure, by different combinations of the public, private, voluntary and community sectors, other services are delivered less formally [14]. Such 'fourth sector' service delivery [15] involves informal neighbouring and time giving on a one-to-one basis in recognition of an 'unmet need' at grassroots level, on the ground. These informal neighborhood community-based services and activities that rely upon localized networks are part of the fabric of rural community life [16], and include a diverse range of activities such as befriending and home visiting by members of church groups, social activities at village halls, informal gatherings and social contact that occurs while accessing services at village post offices or when visiting village pubs [14].

\section{METHODS}

The present study utilised a qualitative research design, specifically the Grounded Theory. This study selected child protection and rehabilitation services as the representative sample for the study. In Malaysia, children 18 years old and below who need protection and rehabilitation services are placed in institutions called Taman Seri Puteri (TSP), Sekolah Tunas Bakti (STB) and Asrama Akhlak (AA). However, in this study, STB Marang which houses the girls was selected using purposive sampling as a sample representative for the study due to a unique requirement of girls which is their reproductive needs.

However, before data collection was carried out, the researcher used theory or concept sampling to ensure that the sampling technique used was appropriate or relevant to the concept and/or theory used to explain the studied social phenomena as described by [17]. At the same time, the snowball sampling technique was used since studies on child welfare networks have never been conducted in Malaysia and the researcher was not aware of the organizations/agencies and individuals involved in the formation of social networks to fulfil the child needs [18].

This study was carried out using one-to-one or face to face, semi-structured interviews based on openended questionnaires that were constructed using the interview protocol. The data collection and data analysis processes in this study were conducted simultaneously as described by [19]. There are six stages in processing and analysing data; i.e. transcription, sorting, coding, themes, demonstration of reliability and validity of data, and reporting [20]. Data processing and analysis were done using NVivo9 software. Data analysis was performed using themes and sub-themes that were determined by the researcher based on the literature review and conceptual frameworks created through coding and annotations based on the nodes that were generated.

\section{RESULTS AND DISCUSSION}

In Malaysia, the government through Ministry of Finance appointed several companies by formal agreement or contract as Panel System Centre Contract between two or more parties under Treasury Directive (AP) 2008. APs are the major financial and accounting regulations in government financial management. This means that the items listed as similar goods should be obtained through companies that have been listed in the Treasury Contract Circular (PKP) and also through the www.treasury.gov.my website. The contract period for listed companies is for a year from $1^{\text {st }}$ January to $31^{\text {st }}$ December each year. 
Food and drink are the basic essentials that are very important to every life. To cater for food and beverage needs to trainees at STB Marang, the welfare services network has been carried out with various social agencies that have been registered with the Ministry of Finance Malaysia. The findings revealed that the social network was created according to the category of food and beverages classified by the Ministry of Finance Malaysia and STB Marang management basis through tenders with social agencies as listed below. The main categories of food and beverage supply details are shown in Table 1 below.

Table 1. Agency and Social Role

\begin{tabular}{|l|l|}
\hline \multicolumn{1}{|c|}{ Agency } & \multicolumn{1}{c|}{ Social Role } \\
\hline Cahaya Piramid (M) Sdn Bhd & Supply Rice \\
\hline Manir / Belara Area Farmers Office & Supply Chicken and Egg Chicken \\
\hline \multirow{2}{*}{ Bread Sukaramai } & $\begin{array}{l}\text { Supply White Bread, Full Bread Mill (whole meal), Ban and } \\
\text { Cakes }\end{array}$ \\
\hline \multirow{4}{*}{ Haji Manaf's Business } & Supply fish \\
\cline { 2 - 3 } & Supplying Vegetables \\
\cline { 2 - 2 } & Supplying Fruits \\
\cline { 2 - 2 } & Supply Mineral Water \\
\cline { 2 - 2 } & Providing Fruit Cord and flavors \\
\hline Company of Mohd bin Abdullah & Supply Gas for Cooking \\
\hline
\end{tabular}

There are also several items of food and beverages that cannot be purchased by STB Marang. This is in line with the Treasury Contract Circular No. 2 of 2015, which lists some items that are not made on a contractual basis by the institution, but are made on a straightforward basis. The items are like noodles, rich series, jam, chili sauce, tomato sauce, soy sauce, tea, coffee and curry/dates spice powder. According to key informants interviewed, purchases for these items are made directly or direct negotiations according to the needs and the number of trainees available to avoid wastage. According to key informants interviewed, these items are sometimes purchased directly through Haji Manaf's Business as the quantity required is small. The main informant (1) says:

"... Usually we just make order ration with Tuan Haji Manaf. The quantity we want to buy is just a little bit. It does not matter if you order or purchase with listed companies. Once upon a time we used the contract system with them. They once cast in large quantities, in bulk. Cannot send in a small amount. After all, the company that sent it from Kuala Lumpur is right. I do not want to send it a little. When much is delivered, we cannot do anything. Not exhaustive. Forced to be dismissed as it was due to date ..."

(Sources: Key Informant (1))

The use of vouchers was also made by the institution to make the payment of the pocket money for the trainers at STB Marang. According to interviewees:

"... Vouchers are sent to Terengganu State Accountant Department. Now I have a voucher.
Then I handed the voucher to the Chief Clerk to be confirmed. Then I hand it over to the principal to approve the voucher. When the principal has passed the voucher, I will enter into the national accounting gateway. But, in the state accountant department, who approved that I was not sure. $O k$, if you have passed the voucher I sent earlier, they will pass in two ways; ie whether payment by check or payment by Electronic Fund Transfer (EFT). If checked, they will issue a check to us. However, if EFT, they will issue EFT numbers and payment will be made into the bank account directly. Normally, if for pocket money I'll ask them to issue a check. When they have checked, I'll go get there ... We have a voucher to the Accountant's Department. We think it is monthly. Every month I will make a voucher ..."

(Sources: Key Informant (3))

Trainers are also allowed to make purchases using their pocket money directly. According to the main interviewer:

"... We first look at whether they are worthy to go out or not. Usually the mother of the case will bring them out outing as a reward to them because they behave well. Usually, they will buy items that we do not set to buy. What we did not provide here. They can only spend money when they're out-outs only. If they do not go out, they will keep in their accounts only their money ..."

(Sources: Key Informant (3))

The three systems adopted proved that STB Marang has been using the quasi market in the provision 
and delivery of social services to children housed under the custody of this institution. This implementation will not only enhance the productivity of the institutions, but more importantly, to improve the well-being of children in STB Marang.

Concerned with the mixed economy of care approach, this study also found that there are various social agencies involved in the welfare services network of children at STB Marang. However, for this study researchers focus on the establishment of a welfare network to meet the needs of food and beverage.

\section{CONCLUSION}

This study also found that the development of child welfare networks in STB Marang is still in its early stages and is not wide enough. Although STB Marang adopts a mixed economy of care through the quasi market, the overall welfare network is too formalized. The welfare network system that is practiced is behind closed doors. The informal sector is not involved in the established welfare network. This has led to challenge on the development of an ongoing welfare network that is not integrated, even though the practice of integrated welfare networks has proven to provide the range of welfare services needed by the target group, especially children to meet their needs and rights.

Therefore, researcher has developed and proposed the Social Network Development Model as shown in Figure 1. From this proposed model, the researcher concludes that the best child welfare network services management system is an open, integrated and constantly developing welfare network. This management system requires the cooperation of the various parties in the social environment in which the child is developing, from parents to community levels, from the micro environment to the macro environment.

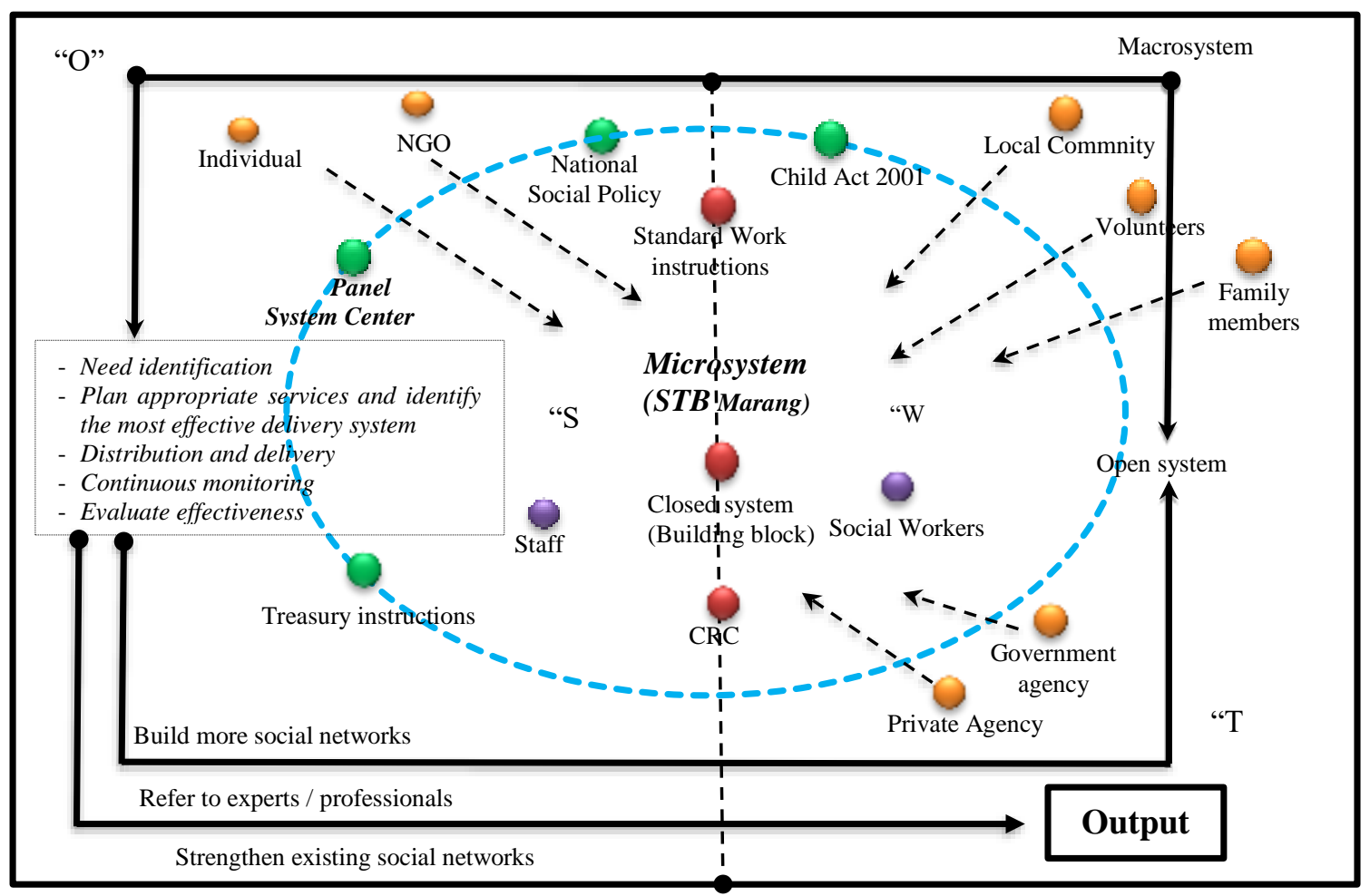

Figure 1 Social Network Development Model

The implementation of this open and integrated management system requires a comprehensive process of delegation of authority from the institution. In order to conduct a delegation of power, the institution must first study the results of the SWOT analysis that was carried out strategically. SWOT analysis-based actions can be taken after taking into account all existing building blocks that hinder the formation of a social network. For example, this study found that the main building block is the Treasury Directive (TD) through the Treasury Contract Circular (TCC) issued by the Ministry of Finance. Therefore, in order to create an integrated and open social network system, these building blocks should be considered as one problem that the government should resolve. This is extremely difficult to accomplish and represents a major challenge in the development of the child welfare networks. More so that STB Marang is one of the nation's leading public care institutions. 
The implementation of this open and integrated management system requires a comprehensive process of delegation of authority from the institution. In order to conduct a delegation of power, the institution must first study the results of the SWOT analysis that was carried out strategically. SWOT analysis-based actions can be taken after taking into account all existing building blocks that hinder the formation of a social network. For example, this study found that the main building block is the Treasury Directive (TD) through the Treasury Contract Circular (TCC) issued by the Ministry of Finance. Therefore, in order to create an integrated and open social network system, these building blocks should be considered as one problem that the government should resolve. This is extremely difficult to accomplish and represents a major challenge in the development of the child welfare networks. More so that STB Marang is one of the nation's leading public care institutions.

The development of welfare networks is seen as a very challenging matter because social networking is built through collaboration, coordination, sharing and strategic planning. Meanwhile, the mixed economy of care should be practiced by the government, especially since the institutions that accommodate children are not able to bear the responsibilities alone. However, researcher believes that every effort and action taken by all parties in an integrated manner will produce a comprehensive and conducive welfare network. Every stage of life that includes children, parents or guardians, family members, the public sector, the private sector, the voluntary sector, community, neighbourhood and individuals have a responsibility to fulfil all the rights of children so that children can have a happy life.

As such, the integration of various social agencies is an excellent platform to meet all of our needs, especially to fulfil the rights of children living in the custody of social institutions. According to [21][22], the integration of various services within an organization can not only change the climate and harmonize an organization, but also provide a variety of results and quality to the services delivered. Whereas, according to [7][10], the collaboration between all parties involved requires continuous effort to achieve the wanted aims. The provision of services to children and family members based on a group approach requires the participation of each agency involved in communicating, collaborating and coordinating all beneficial activities that enable the formation of an integrated welfare network. This is because the formation of integrated networks is a catalyst for the well-being of children, especially children in the care of social institutions.

\section{AUTHORS' CONTRIBUTIONS}

Siti Hajar Abdul Rauf, conducted the research, analyzed the data and drafts the paper. The paper was draft with Siti Balqis Mohd Azam. Siti Hajar Abu Bakar Ah proofread the article and Haris Abdul Wahab check the format and technical.

\section{ACKNOWLEDGMENTS}

We thank to Ministry of Education Malaysia and Center for Research Excellence and Incubation Management (CREIM), University Sultan Zainal Abidin (UniSZA), Gong Badak Campus, Terengganu Malaysia for the permission to conduct this research, all the Child Institutional Social Care and respondents involved in this research for assistance that greatly assisted the research. Fundamental Research Grant Scheme (FRGS) Project under Ministry of Education Malaysia - RR277 (FRGS/1/2018/SS06/UNISZA/02/3)

\section{REFERENCES}

[1] E.C. Roehlkepartain, K. Pekel, A.K. Syvertsen, J. Sethi, T.K. Sullivan, P.C. Scales, Relationships First: Creating Connections that Help Young People Thrive. Minneapolis, MN: Search Institute, 2017.

[2] B.J. West, G.F. Massari, G. Culbreth, R. Failla, M. Bologna, R.I.M. Dunbar, P. Grigolinib, Relating size and functionality in human social networks through complexity. PNAS, 117(31), 2020, 18355 18358.

DOI: https://doi.org/10.1073/pnas.2006875117

[3] J.L. Clark, S.B. Algoe, M.C. Green, Social Network Sites and Well-Being: The Role of Social Connection. Current Directions in Psychological Science, 27(1), 2018, 32-37. DOI: https://doi.org/10.1177/0963721417730833

[4] L. Chawla, Childhood nature connection and constructive hope: A review of research on connecting with nature and coping with environmental loss. People Nat, 2, 2020, 619-642. DOI: https://doi.org/10.1002/pan3.10128

[5] Z. Li, Z. Qiu, How does family background affect children's educational achievement? Evidence from Contemporary China. The Journal of Chinese Sociology, 5(13), 2018, 1-21. DOI: https://doi.org/10.1186/s40711-018-0083-8

[6] J. Przeperski, S.A. Owusu, Children and the Child Welfare System: Problems, Interventions, and Lessons from Around the World. Child Adolescent Social Work J, 38, 2021, 127-130. DOI: https://doi.org/10.1007/s10560-021-00740-5

[7] K. Fong, Child welfare involvement and contexts of poverty: The role of parental adversities, social networks, and social services. Children and Youth 
Services Review, 72, 2017, 5-13. DOI: https://doi.org/10.1016/j.childyouth.2016.10.011

[8] M.A. Siti Balqis, A.B.A. Siti Hajar, M.Y. Jal Zabdi, A.R. Siti Hajar, A case study on academic and vocational training for child offenders undergoing a multisystemic therapy-based rehabilitation order in Malaysia. Children and Youth Services Review, 122, 2021, 1-14. DOI: https://doi.org/10.1016/j.childyouth.2020.105911

[9] T. Elmer, K. Mepham, C. Stadtfeld, Students under lockdown: Comparisons of students' social networks and mental health before and during the COVID-19 crisis in Switzerland. PLoS ONE 15(7), 2020, e0236337. https://doi.org/10.1371/journal.pone.0236337

[10] S. Joseph, J. Sempik, A. Leu, S. Becker, Young Carers Research, Practice and Policy: An Overview and Critical Perspective on Possible Future Directions. Adolescent Res Rev, 5, 2020, 77-89. DOI: https://doi.org/10.1007/s40894-019-00119-9

[11] M. Chalkley, J. Sussex, Private Provision of Publicly Funded Health Care: The Economics of Ownership. OHE Briefing, London: Office of Health Economics, 2018.

[12] J. Wirtz, K.K.F. So, M.A. Mody, S.Q. Liu, H.H. Chun, "Platforms in the peer-to-peer sharing economy", Journal of Service Management, 30(4), 2019, 452-483. DOI: https://doi.org/10.1108/JOSM-11-2018-0369

[13] P. Esposito, S.L. Dicorato, Sustainable Development, Governance and Performance Measurement in Public Private Partnerships (PPPs): A Methodological Proposal. Sustainability, 5696(12), 2020, 1-25. DOI: https://doi.org/10.3390/su12145696

[14] I. Manggat, R. Zain, Z. Jamaluddin, The Impact of Infrastructure Development on Rural Communities: A Literature Review. International Journal of Academic Research in Business and Social Sciences, 8(1), 2018, 637-648.

[15] C. Azlini, A.R. Siti Hajar, Z.M. Lukman, Konsep Penginstitusian Rumah Anak Yatim Miskin di Malaysia. Malaysian Journal of Social Sciences and Humanities, 5(1), 2020, 40-45.

[16] J. Schröders, F.S.T. Dewi, M. Nilsson, M. Nichter, M.S. Sebastian, Effects of social network diversity in the disablement process: a comparison of causal inference methods and an outcome-wide approach to the Indonesian Family Life Surveys, 20072015. International Journal for Equity in Health, 19(128), 2020.2 DOI: https://doi.org/10.1186/s12939-020-01238-9

[17] C. Conlon, V. Timonen, C. Elliott-O'Dare, S. O'Keeffe, G. Foley, Confused About Theoretical Sampling? Engaging Theoretical Sampling in Diverse Grounded Theory Studies. Qualitative
Health Research, 30(6), 2020, 947-959. DOI: https://doi.org/10.1177/1049732319899139

[18] J. Kirchherr, K. Charles, Enhancing the sample diversity of snowball samples: Recommendations from a research project on antidam movements in Southeast Asia. PLoS ONE, 13(8), 2018, e0201710. DOI: https://doi.org/10.1371/journal. pone. 0201710

[19] L.S. Nowell, J.M. Norris, D.E. White, N.J. Moules, Thematic Analysis: Striving to Meet the Trustworthiness Criteria. International Journal of Qualitative Methods, 16, 2017, 1-13. DOI: https://doi.org/10.1177/1609406917733847

[20] J. Sutton, Z. Austin, Qualitative Research: Data Collection, Analysis, and Management. The Canadian journal of hospital pharmacy, 68(3), 2015, 226-231.

DOI: https://doi.org/10.4212/cjhp.v68i3.1456

[21] G.B. Arrington, R.J. Dwyer, Can Four Generations Create Harmony Within a Public-Sector Environment? International Journal of Applied Management and Technology, 17(1), 2018, 1-21. DOI: http://doi.org/10.5590/IJAMT.2018.17.1.01

[22] C. Azlini, A.R. Siti Hajar, Z.M. Lukman, A Cross Cultural Definitions of Orphanages. International Journal of Research and Scientific Innovation, VII(II), 2020, 249-252. 